\title{
Presence of the Potential Toxic Metals (PTMs) in the urban and peri-urban topsoils
}

\author{
Petra Vrhovnik ${ }^{1}$, Matej Dolenec ${ }^{2}$, Anja Ilenič ${ }^{1}$, and Alenka Mauko Pranjić ${ }^{1}$ \\ ${ }^{1}$ Slovenian National Building and Civil Engineering Institute \\ ${ }^{2} 2$ University of Ljubljana, Faculty of Natural Sciences and Engineering
}

July 6,2021

\begin{abstract}
The occurrence of the PTEs contamination in the environment resulting from the point or diffuse sources increases with globalization and population growth. Anyway the benefits of home gardening for the physiological and physical well-being, as well as uncertainties regarding food supply chain in the case of Covid-19, the desire to use home-grown (local) food is increasing more and more. There is no information available on the PTE pollution of urban soils used for the food production in Slovenia. Therefore, the main goal of present study is the characterization of urban gardens and agricultural areas affected by flooded sediments. The total concentrations of PTEs in soil and sediment samples were ICP-MS. The concentrations of PTEs (As, Cd, $\mathrm{Cr}, \mathrm{Cu}, \mathrm{Ni}, \mathrm{Pb}$ and $\mathrm{Zn}$ ) exceeded the permissible limit values defined in Slovenian Official Gazette. To define the natural or artificial origin of PTEs, the mineralogical composition of the selected soils and sediments was determined. The results obtained in present study were correlated with the national background values measured in the upper soil horizon and showed elevated concentrations. In addition to the environmental issues, the social aspect of potential impacts of PTEs on human health and safety was investigated. The results show that despite the numerous local, national and international plans and measures, greater awareness of the general public is needed to understand the hazardous effects of PTEs and the need for appropriate management of contaminated soil in the case contaminated areas.
\end{abstract}

\section{Hosted file}

Draft_manuscript_Vrhovnik et al.docx available at https://authorea.com/users/424054/articles/ 529220-presence-of-the-potential-toxic-metals-ptms-in-the-urban-and-peri-urban-topsoils

\section{Hosted file}

Tables.docx available at https://authorea.com/users/424054/articles/529220-presence-of-thepotential-toxic-metals-ptms-in-the-urban-and-peri-urban-topsoils 

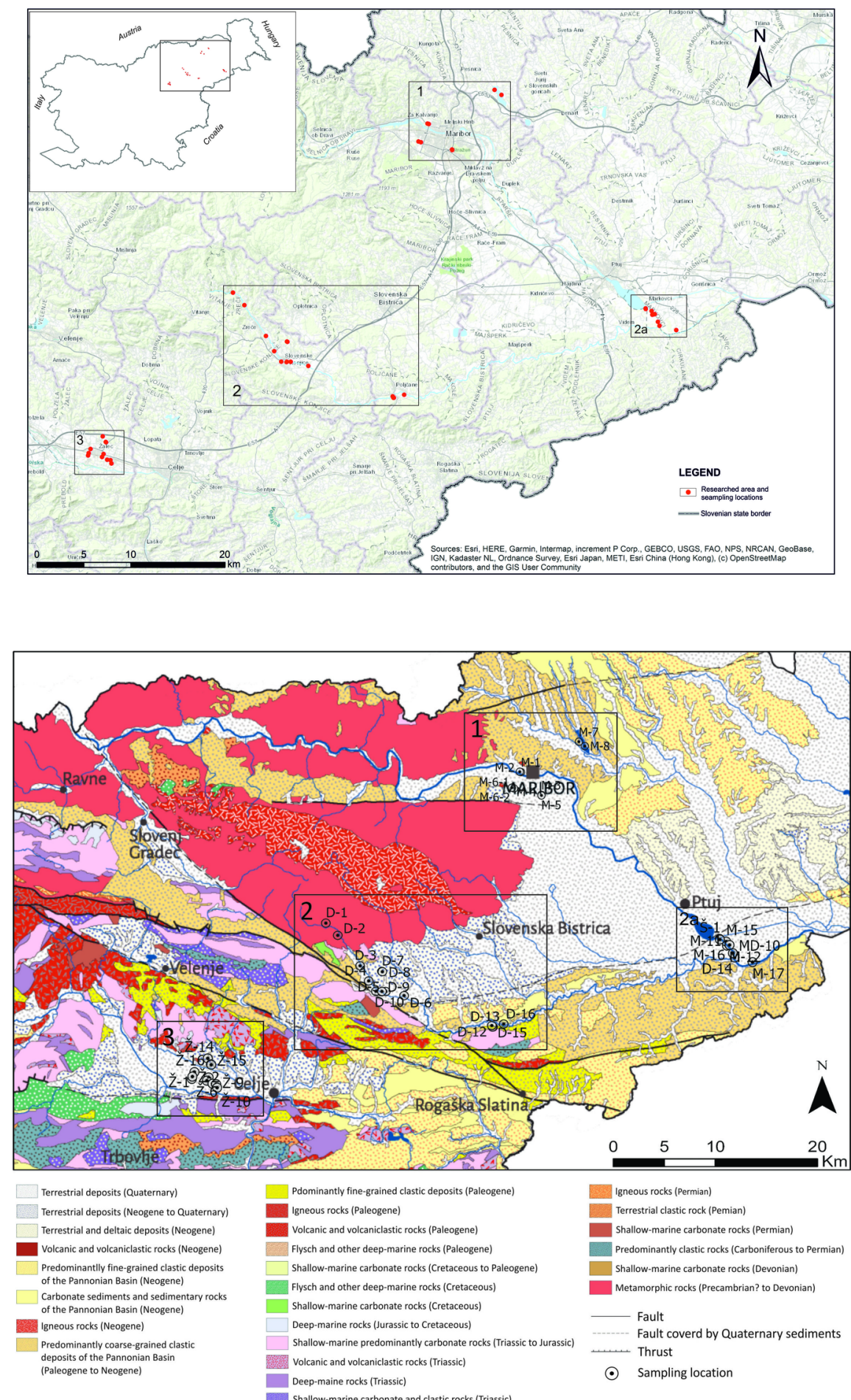

Ineous rocks (Permian)

Terrestrial clastic rock (Pemian)

Thallow-marine carbonate rocks (Permian) Predominantly clastic rocks (Carboniferous to Permian)

Shallow-marine carbonate rocks (Devonian)

Metamorphic rocks (Precambrian? to Devonia - Fault

Fault coverd by Quaternary sediments -...- Thrust

- Sampling location

Shallow-marine carbonate and clastic rocks (Triassic) 

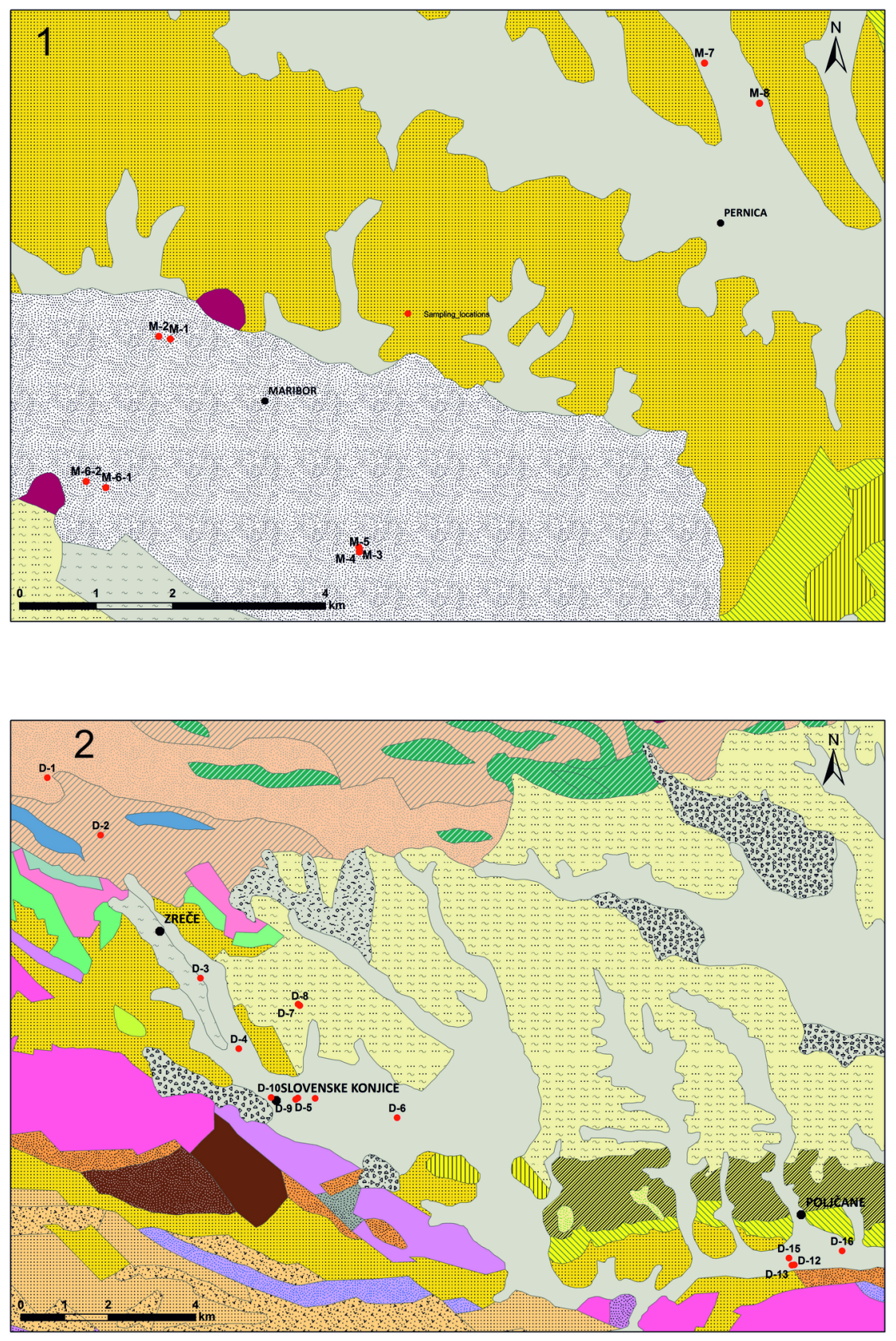

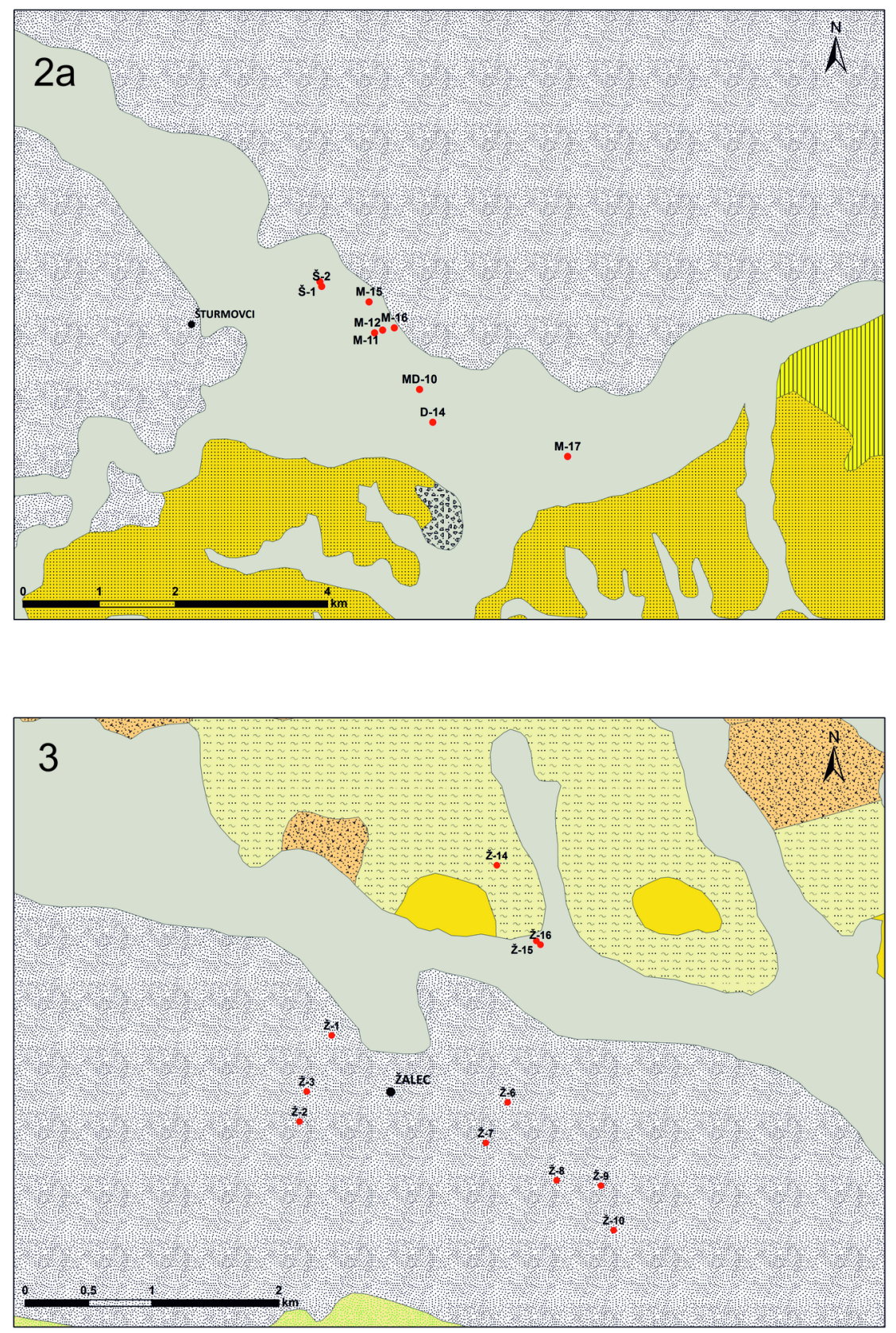

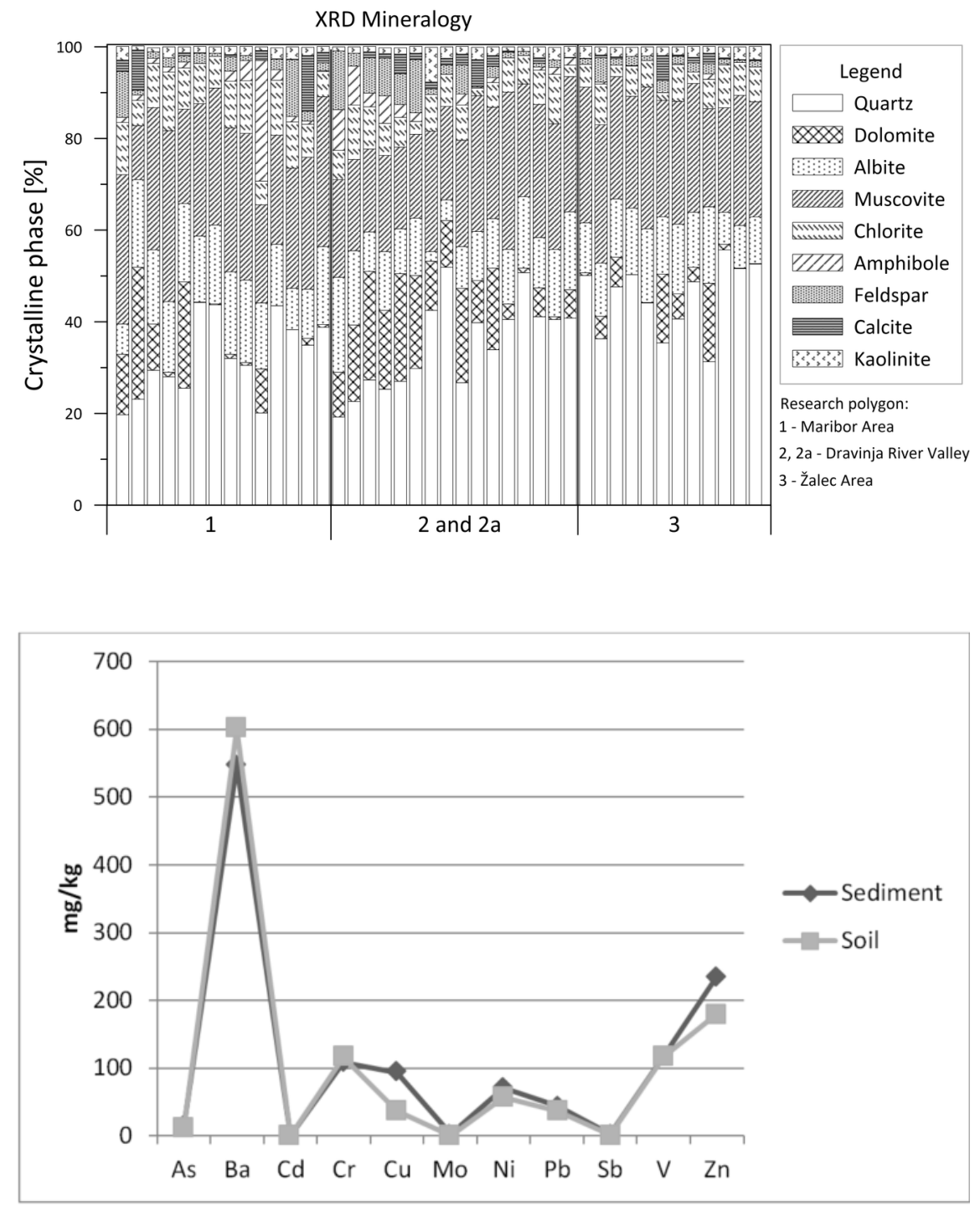